\title{
Lowland tapir distribution and habitat loss in South America
}

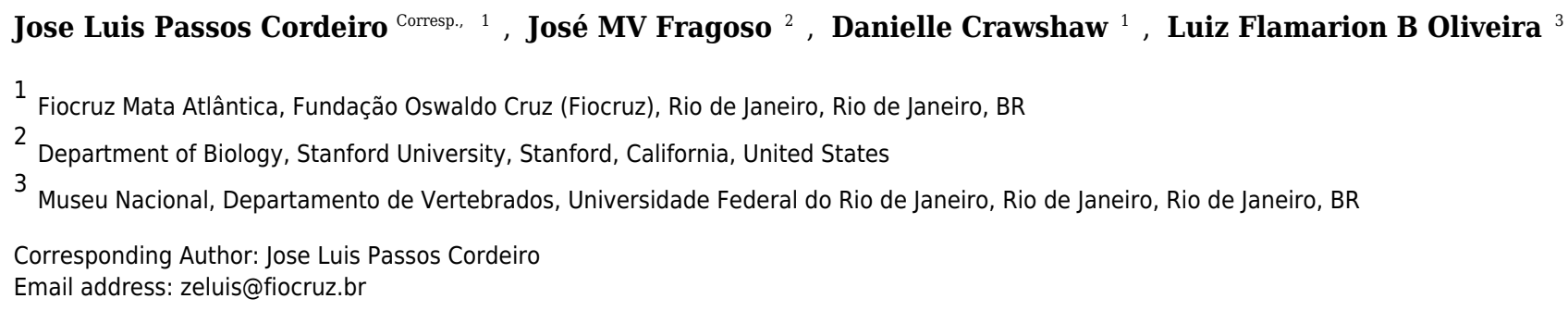

The development of species distribution models (SDMs) can help conservation efforts by generating potential distributions and identifying areas of high environmental suitability for protection. Our study presents a distribution and habitat map for lowland tapir in South America. We also describe the potential habitat suitability of various geographical regions and habitat loss, inside and outside of protected areas network. Two different SDM approaches, MAXENT and ENFA, produced relative different Habitat Suitability Maps for the lowland tapir. While MAXENT was efficient at identifying areas as suitable or unsuitable, it was less efficient (when compared to the results by ENFA) at identifying the gradient of habitat suitability. MAXENT is a more multifaceted technique that establishes more complex relationships between dependent and independent variables. Our results demonstrate that for at least one species, the lowland tapir, the use of a simple consensual approach (average of ENFA and MAXENT models outputs) better reflected its current distribution patterns. The Brazilian ecoregions have the highest habitat loss for the tapir. Cerrado and Atlantic Forest account for nearly half (48.19\%) of the total area lost. The Amazon region contains the largest area under protection, and the most extensive remaining habitat for the tapir, but also showed high levels of habitat loss outside protected areas, which increases the importance of support for proper management. 


\section{Lowland tapir distribution and habitat loss in South America}

2

3 José Luís Passos Cordeiroํㅜ José M.V. Fragoso ${ }^{2}$, Danielle Crawshaw ${ }^{1}$, Luiz Flamarion B.

4 Oliveira $^{3}$

$5{ }^{1}$ Fiocruz Mata Atlântica, Fundação Oswaldo Cruz (Fiocruz), Rio de Janeiro, RJ, Brasil

$6 \quad{ }^{2}$ Department of Biology, Stanford University, Stanford, U.S.A.

$7 \quad{ }^{3}$ Setor de Mastozoologia, Departamento de Vertebrados, Museu Nacional, Universidade Federal

8 do Rio de Janeiro, Rio de Janeiro, RJ, BR.

9 Corresponding Author:

10 José Luís Passos Cordeiro ${ }^{1}$

11 Estrada Rodrigues Caldas, 3400, Jacarepaguá, Rio de Janeiro, RJ, 22713-375, BR

12 Email address: zeluis@fiocruz.br 


\section{ABSTRACT}

The development of species distribution models (SDMs) can help conservation efforts by generating potential distributions and identifying areas of high environmental suitability for protection. Our study presents a distribution and habitat map for lowland tapir in South America.

We also describe the potential habitat suitability of various geographical regions and habitat loss, inside and outside of protected areas network. Two different SDM approaches, MAXENT and ENFA, produced relative different Habitat Suitability Maps for the lowland tapir. While MAXENT was efficient at identifying areas as suitable or unsuitable, it was less efficient (when compared to the results by ENFA) at identifying the gradient of habitat suitability. MAXENT is a more multifaceted technique that establishes more complex relationships between dependent and independent variables. Our results demonstrate that for at least one species, the lowland tapir, the use of a simple consensual approach (average of ENFA and MAXENT models outputs) better reflected its current distribution patterns. The Brazilian ecoregions have the highest habitat loss for the tapir. Cerrado and Atlantic Forest account for nearly half (48.19\%) of the total area lost. The Amazon region contains the largest area under protection, and the most extensive remaining habitat for the tapir, but also showed high levels of habitat loss outside protected areas, which increases the importance of support for proper management.

\section{Keywords} Planning; Protected Areas. 


\section{INTRODUCTION}

The lowland tapir (Tapirus terrestris) is the largest terrestrial vertebrate (autochthone) in

its ecosystems. Considered a keystone species, due to its large size and biomass, and also due to its function as seed predator/disperser (Bodmer, 1991; Rodrigues, Olmos \& Galetti, 1993; Fragoso, 1997; Fragoso, 2005; Taber et al., 2009; Medici, 2010). Tapirs inhabit a variety of habitats, from xeric formations such as the Gran Chaco, to tropical dry forests and wetter formations such as rain forests, gallery forest, shrub forests, savannas and grasslands (Nowak, 1991; Fragoso \& Huffman, 2000). These vegetation types however, are used unevenly, with tapirs exhibiting selective habitat use. For example, they seem to prefer areas with moist palm 
59

60

61

and competition with livestock. Most of the main habitat out of Amazon has been converted to human use as cattle ranching and agriculture in a short time. The species is completed absent in vast areas of its historic range (Naveda et al., 2008; Taber et al., 2009). Deforestation and other forms of habitat change have all contributed to population declines. Therefore, the understanding the role of variables associated with the original distribution patterns are crucial to partitioning factors involved in the viability of populations. Accordingly, large-scale assessments may show patterns which locally are not evident, but involved in the viability of populations and, to a great extent, the impacts of changes in the long-term.

Species occurrence may be related to set of predictors ranging from site to landscape scale, as range of natural vegetation, terrain attributes, disturbance and human scenarios as land use and protected areas, and other environmental variables as those characterizing climate and seasonal changes (Franklin, 2009; Peterson et al., 2011). Such comprehensive ecological evaluation, including species responses to global changes may be effective when incorporating a large area perspective, particularly in the tropics where data deficient species are the rule or vast areas have been transformed without adequate inventories.

Tapir, despite being a large mammal in the context of the Neotropics, is still data deficient in the largest data set collected for a species with wide distribution (Taber et al., 2009). However, the available data allows insights on their response to ecological factors along the ecogeographical regions and major habitats, and can support conservation planning showing patterns of response to ecological and human factors in the time scale.

Identifying the most important environmental parameters bounding species distributions remains difficult because animals respond to the environment at a range of spatial scales (Krausman, 1997 ). Ungulates for example, make foraging decisions both within and across a 
82 variety of spatial scales, making it difficult to relate species to specific habitats across their entire

83

84 species range (Hobbs, 2003). However, describing these relationships is an important first-step towards understanding linked ecological processes and guiding conservation decision-making, as the agents that determine population viability may include factors related to habitat or elements that transcend spatial scales, such as dynamically linked variables or unlinked elements (Peterson, 2011). Species Distribution Models (SDM) are thus important tools for defining testable hypotheses and generating potential species' ranges. Clements et al. (2012) and Mendoza et al. (2013) produced a SDM for Asian tapir (Acrododia indica) and Baird's tapir (Tapirella bairdii), respectively, and demonstrated the applicability of SDM use in the evaluation and development of tapir conservation strategies. Norris (2014) applied SDM to understanding the distribution of lowland tapir in a fragment of Atlantic forest in southeast Brazil and highlight the importance of a fundamental understanding of species natural history to determine not only appropriate model parameters, but also the biological relevance of SDMs.

Appropriate model selection is critical when ecological as well as distribution oriented hypotheses are to be tested. The selection of a SDM should consider the theoretical underpinnings and practical applicability of the model as well as the hypothesis of interest (Jiménez-valverde, Lobo \& Hortal, 2008; Kamino et al., 2011). Ecological Niche Factor Analysis (ENFA) and MAXENT are two approaches that are presently used for describing distributions and classifying landscape suitability for species (Braunisch \& Suchant, 2010; Rebelo \& Jones, 2010; Rodríguez-Soto et al., 2011).

ENFA generates species distributions based on Hutchinson's concept of the ecological niche by comparing known species locations and associated environmental variables to areas without locations but with the same environmental conditions (Hirzel et al., 2002). In contrast, 
MAXENT'S theoretical underpinnings are based on the maximum entropy principle and mathematically similar to a Poisson regression model (Renner \& Warton, 2013). We modeled the potential distribution of the lowland tapir in South America using both methods and evaluated their relative accuracy.

The objective of this study was to describe habitat suitability, potential distribution and quantification of habitat loss (total and per ecoregions) for T. terrestris over its entire range, to evaluate and contribute to the knowledge about the species' conservation status.

\section{MATERIALS \& METHODS}

\section{Occurrence data}

In our analyses we used 625 lowland tapir location points, 500 for modeling (Table S1) and an independent 125 for testing (validating) (Table S2) the generated distributions. Location data were obtained from (Brooks, Bodmer \& Matola, 1997; Anderson, 1997; Simonetti \& Huareco, 1999; Patterson et al., 2003; Florez FK, Rueda CF, Peñalosa W, et al. 2008.), and a data set developed from expert consultation and our own fieldwork.

\section{Environmental descriptors}

We used eight (8) environmental variables $\left(0.04^{\circ}\right.$ of spatial resolution, $\left.\sim 5 \mathrm{~km}\right)$ of which 6 climatic variables of WorldClim (Hijmans et al.,2005), as well as altitude and vegetation index (Table 1). These variables are commonly used in predictive species distribution, and represent a set of easily interpreted ecological variables.

\section{Distribution Models}

We used ENFA version BioMapper 4.0 (Hirzel, Hausser \& Perrin, 2007) and MAXENT version 3.2.3a (Phillips, Anderson \& Schapire, 2006) models to describe habitat suitability and 
127 potential tapir distributions. Both methods use environmental data linked to species location 128 points and relate this to environmental variables across the area of interest. For the T. terrestris

Consensual Habitat Suitability Map (CHSM) the simple average of all models outputs was calculated. For the $T$. terrestris potential distribution binary map (suitable/unsuitable), we applied the Minimum Training Presence (MTP) as a threshold value for models and CHSM, because it is the most conservative threshold, identifying the maximum predicted area possible while still maintaining a zero omission rate for both training and test data. Norris (2014) identifies MTP with more appropriate threshold criteria for $T$. terrestris, based on its own broad distribution and variety of habitats used by the species.

Additionally, for comparative purposes, the images resulting from each of the ENFA and MAXENT models (with continuous values from 0 to1) were reclassified into five environmental suitability zones, 1) an Unsuitable Zone (UNSZ; value pixel suitability $<$ Minimum Training Presence, MTP), 2) a Low Suitability Zone (LSZ, value pixel suitability between MTP value and $0.25), 3$ ) an Intermediate Suitability Zone (ISZ, value pixel suitability between 0.25 and 0.50 ), 4) a High Suitability Zone (HSZ, value pixel suitability 0.50 and 0.75 ), and 5) a Very High Suitability Zone (VHSZ, value pixel suitability $>0.75$ ).

\section{Ecological Niche Factor Analysis (ENFA)}

The ENFA approach uses a factor analysis similar to Principal Component Analysis when producing species distributions (Hirzel et al., 2002). ENFA analyzes many environmental variables $(\mathrm{EV})$ and reduces them to a few uncorrelated factors. This information is then used to produce an ecologically influenced species distribution. In ENFA all factors have ecological weight. The first factor is called Marginality (M), and measures the difference between the average conditions at sites where individuals of the species where actually located (species 
150 distribution) compared to sites throughout the entire area of interest (global distribution), to

151 produce a distribution of the species' niche in this environmental space. Another factor that is

152 also considered is Specialization (S), which is the ratio of global variance to species variance.

153 This item is a measure of niche breadth for the species (Braunisch et al., 2008). An M value

154 close to one indicates that the species is a habitat specialist relative to the average condition of all

155 EVs. The inverse of Specialization $(1 / \mathrm{S})$ is global Tolerance $(\mathrm{T})$, which is a measure of the

156 ecological flexibility of the species. A low value of $\mathrm{T}$ (close to 0 ) identifies a "specialist" species

157 that tends to live in a very narrow range of conditions. A high value of $\mathrm{T}$ (close to 1 ) indicates a

158 species that is not very selective of its living environment.

A Habitat Suitability Map (HSM) factor is calculated using the median - extremum algorithm derived from the first factors. This is the preferred algorithm for use when the real optimum is located at the extremes of the environmental conditions. We used broken-stick heuristics to determine the number of significant factors that should be retained to calculate habitat suitability (see, Jackson ,1993).

\section{MAXENT}

MAXENT uses a machine learning response to predict species distributions from incomplete data. This method estimates the most uniform distribution (maximum entropy) of the sampled points relative to background locations across the study area. It produces a model of a species' environmental requirements based only on presence data and a set of environmental variables (Phillips, Anderson \& Schapire, 2006).

MAXENT assumes that sampling of presence locations is unbiased. In MAXENT spatial biased sampling promotes model inaccuracy (Phillips, Anderson \& Schapire, 2006; Phillips et al., 2009; Syfert, Smith \& Coomes, 2013). To account for the spatial bias in presence records, we 
173 used the bias grid (Fig. S1), following procedures outlined by Elith, Kearney \& Phillips (2010).

174 The bias grid is used to down-weight the importance of presence records from areas with more

175 intense sampling. The weighting surface is calculated based on the number of presence records

176 within an area around any given cell (weighted by a Gaussian kernel with a standard deviation of

$177100 \mathrm{~km})$.

MAXENT also provides environmental variable response curves indicating how each variable affects the predicted distribution. We ran MAXENT to model lowland tapir distribution under the 'auto-features' mode and the default settings with 10-fold replicates (jack-knife crossvalidation). The logistic output was used (habitat suitability on a scale of $0-1$ ), with higher values in the Habitat Suitability Map (HSM) representing more favorable conditions for the presence of the species (Elith et al., 2006; Phillips \& Dud1, 2008).

\section{Model Validation and Comparison}

Although validation procedures based on resampling of input data have some merit in simulating species occurrence, they fail to provide the same degree of confidence as when using an independent dataset (Greaves, Mathieu \& Seddon, 2006). Thus, to evaluate the predictive capacity of the models, two approaches were used: the first - Model Fit - tested the fit of occurrence points to the generated models; for ENFA using the Boyce index (B) with 10-fold jack-knife cross-validation (for more details, see Boyce et al., 2001; and Hirzel et al., 2006). For the MAXENT model, we used 10-fold replicates (jack-knife cross-validation) to obtain the average Area Under Curve (AUC) of the Receiver Operating Characteristics (ROC) analysis. The second approach used was - Field Truth; this validation method used an independent set of 125 actual occurrence records (randomly selected from total points and not used in the generation of models) to evaluate the predictive capacity of the models. The predicted suitability 
196 of the models was extracted for each test point, and the average suitability was used to evaluate

197 the model accuracy.

202

203

204

205

206

207

We compared the generated ENFA and MAXENT lowland tapir models using Fuzzy index for continuous maps, and Kappa index for potential distribution binary maps (suitable/unsuitable through MTP threshold criteria) using the Map Comparison Kit v.3.2 software developed by the Netherlands Environmental Assessment Agency (Visser \& Nijs, 2006). Both indices express the pixel similarity for a value between 0 (fully distinct) and 1 (fully identical).

Additionally we used Olson et al.'s delineation (Olson et al., 2001) of the terrestrial "Ecoregions of the World" as our base map (Fig. 1) to better demonstrate the comparison between models and to quantify habitat loss in a South American ecoregions context.

\section{Potential distributions versus remaining natural vegetation and protected areas}

In order to identify both habitat availability and how effective the existing protected areas network is for T. terrestris, a Consensual Potential Distribution Map (CPDM, derived from CHSM - Consensual Habitat Suitability Map - reclassified as suitable and unsuitable, based on MTP cutoff criteria), was overlaid with the Land Cover Map for South America (Eva et al., 2002), upgraded for Brazil (MMA, 2009), and with the WDPA map of protected areas (WDPA, 2014). For these analyses the Land Cover Map for South America was reclassified as Anthropic, Grassland and Forest classes and the protected areas network was subdivided into two categories: Strict Protection (IUCN Categories I, II, III and IV) and Sustainable Use areas (IUCN Categories V, VI and Indigenous Territories identified in WPDA map). 
217

218

\section{RESULTS}

\section{Lowland Tapir Distribution with ENFA}

The ENFA model explained $85.5 \%$ of the information (100\% of the Marginality and $71 \%$ of the Specialization) based on the two factors selected by the broken-stick heuristics criterion for extrapolating lowland tapir distributions (Fig. 2A). Cross-validation of the model quality resulted in a Boyce index of $0.62 \pm 0.14$, indicating a satisfactory predictive capacity (model fit). Analysis of the average suitability of test records using Field Truth produced a value of 55.48 (SD 28.15), indicating high accuracy for the model, since this average value corresponds to the High Suitability Zone for the species. Fig. 2B represents the ENFA potential distribution binary map (suitable/unsuitable) based on the Minimum Training Presence cutoff criteria (MTP=0.02). An overall $\mathrm{M}$ value of 0.57 and $\mathrm{T}$ of 0.52 , indicates that lowland tapir habitat differs moderately from the average conditions across the entire distribution area, suggesting the species is moderately tolerant of a range of conditions. The $\mathrm{M}$ factor alone accounted for $35 \%$ of the total specialization, indicating an intermediate niche breadth for lowland tapirs (see Hirzel et al., 2004).

The relative contribution of EV to the ENFA marginality factor (Fig. 3A) indicates that lowland tapirs "prefer" (more suitability) warm-humid areas with dense forest cover (Annual Mean Temperature between $21^{\circ} \mathrm{C}$ and $27^{\circ} \mathrm{C}$; Mean Temperature of Warmest Quarter between $23{ }^{\circ} \mathrm{C}$ and $28^{\circ} \mathrm{C}$; Mean Temperature of Coldest Quarter between $18^{\circ} \mathrm{C}$ and $25^{\circ} \mathrm{C}$; Annual Precipitation of 1076 - 2654mm; Precipitation of Wettest Quarter of 485 - 1023mm; higher values of NDVI) and avoid high altitude areas. The highest specialization for the species (Fig. 3A) was associated with the temperature variables (Annual Mean Temperature, Mean 
239 Temperature of Warmest Quarter, Mean Temperature of Coldest Quarter, respectively), showing 240 some sensitivity (low tolerance) to shifts away from their optimal values on these variables. An overlay of the ENFA-identified VHSZ and HSZ areas with Olson et al.'s (2001) delineation of the terrestrial ecoregions of the world shows that the best areas for lowland tapirs occur in Tropical Moist Broadleaf Forests (Fig. 1 and 2A). The Tropical Moist Broadleaf Forests of the northern Brazilian Amazon, southern Venezuela and the lowlands of Colombia and Peru, northern Cochabamba and southern Beni Department of Bolivia where also identified as VHSZ areas for lowland tapirs. In contrast, areas south and east of Amazon River basin, the Llanos Savannas biome of Venezuela and Colombia, and the central and north Cerrado Biome (Brazil) were deemed as slightly less (HSZ) suitable for lowland tapirs. An ISZ was identified in the western portion of the Cerrado, the Pantanal Wetland, Atlantic Forests (mainly the coastal region), Chiquitano and Dry Forests regions. The least suitable (LSZ) vegetation types are southern subtropical grasslands, southwestern thorn scrub vegetation of the Dry Chaco biome and the eastern (west of Atlantic Forests) transition zone between Caatinga, Cerrado and Atlantic Forest regions of Brazil. These areas are dominated by tropical seasonal semi deciduous forests (Oliveira-Filho, Jarenkow \& Rodal, 2006) and apparently delineate the distributional limit of lowland tapirs. A large part of the Caatinga biome was classified as unsuitable (UNSZ) for lowland tapirs, particularly the eastern half of this region.

\section{Lowland Tapir Distribution with MAXENT}

With an average AUC of 0.804 (SD=0.01; 10-fold replicates), the MAXENT model (Fig. 2C) achieved a satisfactory model fit and the modeled distribution performed better than random. A Field Truth value of $51.13(\mathrm{SD}=13.51)$ indicates that the model achieved high accuracy. This average value corresponds to the High Suitability Zone for lowland tapirs. Fig. 2D represents the 
MAXENT potential distribution binary map (suitable/unsuitable) based on the MTP cutoff criteria $(\mathrm{MTP}=0.08)$.

The Mean Temperature of the Coldest Quarter (MTCQ) was the variable with the highest gain and which most decreased gain when omitted (when used in isolation) from the model (Fig. 3B). The response curves (Fig S2) for the EV of this model indicate that lowland tapirs are strongly associated with warmer regions (MTCQ between $15^{\circ} \mathrm{C}$ and $23^{\circ} \mathrm{C}$, and AMT between $20^{\circ} \mathrm{C}$ and $25^{\circ} \mathrm{C}$ ) and areas with an annual precipitation over $1000 \mathrm{~mm}$ (suitability of presence $>$ $0.5)$.

With MAXENT the VHSZ areas for lowland tapirs were very restricted to the Eastern Cordillera Real Montane forests in Ecuador. The slightly lower quality HSZ areas prevail in the northern Tropical Moist Broadleaf Forests biome of Colombia, Ecuador and Bolivia. This zone also predominates in Paraguay, northern Argentina, Atlantic Rainforest, the Pantanal Wetland, and the Chiquitano Dry Forests of Bolivia. The ISZ equaled the biggest area identified by MAXENT. The LSZ was found in the Caatinga Biome, in the subtropical highland grassland in the south of the Atlantic Rainforest Biome, and the southern range of its modelled distribution. Some parts of the Caatinga (areas surroundings the São Francisco River, Brazil) biome were classified as LSZ, but the region immediately to the west - a transition area between the Caatinga and Cerrado - supports relatively high values of suitability (ISZ).

\section{Comparison of Models and Consensual Habitat Suitability Map (CHSM)}

The spatial similarity between HSMs produced by the ENFA and MAXENT was moderate, as indicated by the intermediate value of the Fuzzy (0.53). However, if the cutoff limit for suitability is MTP, the Kappa similarity value is very high (0.80) between the models, indicating a similar geographical range between predicted distributions. 
In the CHSM (Fig. 4A) areas with higher habitat suitability values (VHSZ and HSZ) were

286

287 identified in the Amazon region, Pantanal Wetland, Humid Chaco in Paraguay, and the Chiquitano Dry Forests of Bolivia. The Caatinga biome and the southern border of the modeled distribution correspond to areas with less habitat suitability in this map (LSZ). The MTP cutoff criteria (MTP=0.06) was applied to this map (CHSM) to generate the Consensual Potential Distribution Map (CPDM) shown in Fig. 4B.

For a more conservative approach the overlap between the modeled area and the known Tapirella bairdii non sympatric distribution with T. terrestris, on the Pacific coast in Colombia and Ecuador (Brooks, Bodmer \& Matola, 1997; Patterson et al., 2003; Schank et al. 2015), was withdrawn from the final map CPDM (for more details see the discussion section).

\section{Potential distributions (CPDM) versus remaining natural vegetation and protected areas}

The Consensual Potential Distribution Map (CPDM) covers 13,441,402 km², of which $29.44 \%$ are anthropogenic, such that $9,484,379 \mathrm{~km}^{2}$ are available for the species (Table 2). The Atlantic Forests, Chocó Darién Moist Forests, Caatinga biome and Tropical and Subtropical Dry Broadleaf Forests (extreme north of South America) are the ecoregions with the largest individual habitat losses (Table 2). However, considering the size of the lost area (in $\mathrm{km}^{2}$ ), the Cerrado, Atlantic Forest and Amazon Region (Tropical and Subtropical Moist Broadleaf Forests) presented the largest losses. The Amazon region represents $62.73 \%\left(5,949,846 \mathrm{~km}^{2}\right)$ of the total $\left(9,484,379 \mathrm{~km}^{2}\right)$ suitable and remaining area for T. terrestris.

In this context, the protected areas network covers/protects $23.66 \%\left(3.179 .573 \mathrm{~km}^{2}\right)$ of the total suitable area for T. terrestris, as follows: $848,278 \mathrm{~km}^{2}$ Strict Protection and 2,331,295 km² Sustainable Use. Only $6 \%$ of the remaining Cerrado area suitable for lowland tapir is within a 
307 Strict Protection protected area. For the Atlantic Forest and Amazon region the remaining area

308 under strict protection is $10 \%$.

309

310

311

312

313

\section{DISCUSSION}

Our study presents a distribution and habitat map for lowland tapir in South America. We also describe the potential habitat suitability of various geographical regions, habitat loss and assessment of the effectiveness of a protected areas network. Additionally, we evaluated the predictive capacity of two modeling approaches for describing these patterns.

While the environmental requirements identified by the ENFA and MAXENT-modeling approaches for describing lowland tapir range appears broadly similar, only the ENFA model identified forest cover density (NDVI) as a factor contributing to tapir habitat suitability. This resulted in ENFA identifying the Amazon Region as a VHZ or HSZ for lowland tapirs (overlay of Fig. 1 and 2A). This result is supported by field knowledge on the ecology of this species, where tapirs have been identified as strongly associated with warm and wet regions (Bodmer, 1991; Fragoso, 1997; Tober, 2008; Taber et al. 2009).

In contrast, MAXENT identified much of the Amazon Region as an area of lower suitability for tapirs (ISZ; Fig. 2C), This result, in spite of using the bias grid, is related to an idiosyncrasy of the technique, in that MAXENT establishes a complex (very parameterized) and strong fit (over fit) between dependent and independent variables (Jiménez-valverde, Lobo \& Hortal, 2008; Kamino et al., 2011; Rangel \& Loyola, 2012). This explains why the relatively low number of tapir records in the very large Amazon region led MAXENT to identify the region as a lower suitability zone for lowland tapirs. In contrast, results from areas at the climatic extreme of tapir tolerance, such as the xeric Central Chaco, where more records were available, where identified counter intuitively (based on ecological field information) by MAXENT as highly 
330

331

332

333

suitable for tapirs. This classification reflects a bias in the distribution pattern of occurrence records that is related to the difficulty of conducting research in the vast, remote Amazon region (Brooks, Bodmer \& Matola, 1997) relative to more easily accessed, spatially restricted biomes, rather than to the real suitability of areas of lowland broadleaf forests for lowland tapirs. Both models identified the Chocó-Darién Moist Forests ecoregion (western end of Colombia and Ecuador) as suitable for the lowland tapir (Fig. 1 and 2). This region is also the known South American range limit for the Central American Baird's tapir. This potential area of overlap for the two tapir species occurs because of the environmental similarity of this ecoregion (within the context of EV used) with adjacent areas-such as the Magdalena-Urabá moist forests which contain records of lowland tapirs and form a continuous corridor with the lowland forests of the western Andes up to a bottleneck region between the Pacific ocean and the western slope of the Andes in southeastern Ecuador. The presence or absence of either tapir species in this region may be partially related to interspecific interaction between the species. The models in the context of EV used did not detect this possibility. This aspect (limitation) of both models, combined with the already described $T$. terrestris distribution, were the main reasons for excluding this region from the potential distribution map (CPDM) for the analyses of remaining habitats availability and effectiveness of the protected areas network.

\section{CONCLUSIONS}

Apparently viable tapir populations in the protected areas of eastern Brazil (Medici, 2010; Eduardo, Nunes \& Brito, 2012) were classified as falling into LSZ, ISZ or HSZ, depending on the modeling method used. Tapir population levels here are low and this information is linked to the forest types by the models. However, low population levels here are likely the result of human activities that have decreased tapir densities, such as hunting and habitat destruction, 
353 rather than environmental factors (Taber et al., 2009). That is, the forests of eastern Brazil and 354 their transition zones to the seasonal forests of the adjacent Caatinga and Cerrado regions of 355 eastern Brazil have had their tapir populations reduced or extirpated by anthropogenic impacts, 356 so that low population sizes are now associated with these ecosystems and are interpreted by the 357 model, which does not separate anthropogenic variables from non-anthropogenic variables, as 358 being correlated with the ecosystem.

In this context, our results indicate that Brazilian ecoregions have the highest habitat loss for the tapir, which supports the results obtained by Taber et al. (2009) and Medici et al. (2012). Cerrado and Atlantic Forest account for nearly half (48.19\%) of the total area lost $(1,906,948$ of $\left.3,957,023 \mathrm{~km}^{2}\right)$.

When associated to the well-known hunting pressure and elevated habitat loss for the Caatinga, our low habitat suitability results for this biome support the hypothesis of a probable local extinction of tapir indicated by Taber et al. (2009). The same logic can be applied to the southern limit of the tapir distribution area within the Pampa region (Temperate, Tropical and Subtropical Grassland, Savannas, and Shrublands Ecoregions).

The Amazon region contains the largest extent of land under protection, and the most extensive remaining habitat for the tapir, but also showed high levels of habitat loss outside protected areas. This increases the importance of adequate monitoring of protected areas, so as to determine the relative effectiveness of indigenous territories, strict protection areas and sustainable use areas in sustaining tapir populations and inform the management of these areas. Management and use by humans is an inherent characteristic of an area; once the impact of management category on tapir populations is understood, this information can be added to habitat suitability models. 
In conclusion, MAXENT and ENFA produced different HSM for the lowland tapir.

377 While MAXENT was efficient at identifying areas as suitable or unsuitable, it was less efficient

378 (when compared to the results by ENFA) at identifying the gradient of habitat suitability.

MAXENT is a more multifaceted technique that establishes more complex relationships between dependent and independent variables. It is an excellent tool for describing spatial occurrence data; however, spatial aggregation of occurrence records can lead to the miss-classification of areas as highly suitable when they are not, and the identification of areas that are highly suitable as exhibiting poor or no suitability for the species. As conservation planners and ecologists we should remember the axiom that "... all models are wrong, the practical question is how wrong do they have to be before they are not useful" (Box \& Draper, 1987).

If the objective of a conservation or research program is to identify areas that are environmentally very similar to the points where species have been noted, without concern for understanding the ecological and human factors that contribute to that occurrence, then MAXENT is well suited for the task. However, our results indicate that ENFA is more appropriate for the task of classifying habitat suitability zones and species distribution patterns, not only because of the accuracy of the generated models but also due to this method's ability to better identify the gradient of habitat suitability across the potential distribution range, rooted in solid and clear (easy interpretation of parameters) ecological theory (Rangel \& Loyola, 2012).

All tapir species are considered as being at risk throughout their ranges (TSG-IUCN, 2015). While the lowland tapir still exhibits robust populations in much of its extensive range, in other very large areas populations have become fragmented and highly threatened. Conservation planning for the four species, especially those that are listed in red data books, requires the use of the most robust methods for determining potential population size, abundance patterns, 
399 distribution and factors influencing these variables. Our results demonstrate that for at least one 400 species, the lowland tapir, the use of a consensual approach better reflected its current 401 distribution patterns, confirming the critical situation of this species in Brazilian ecoregions.

402 Given that many governments and NGOs now use modeling techniques to assess species 403 habitat suitability zones and distribution patterns for conservation planning, we strongly 404 recommend that care be taken to select the most appropriate model. 


\section{Acknowledgments}

408

409

410

411

412

413

41

415 416

417 information on species distribution. 
420

421

422

423

424

425

426

427

428

429

430

431

432

433

434

435

440

441

\section{References}

Anderson S. 1997. Mammals of Bolivia, taxonomy and distribution. Bulletin of the American Museum of Natural History 231:1-652.

Bodmer RE. 1991. Strategies of seed dispersal and seed predation in Amazonian ungulates. Biotropica 23:255-261. doi: 10.2307/2388202

Box GEP, Draper NR. 1987. Empirical Model-Building and Response Surfaces. 1rst ed. New York: John Wiley \& Sons. 688 p.

Boyce MS, Vernier PR, Nielsen SE, Schmiegelow FK. 2002. Evaluating resource selection functions. Ecological Modelling 157:281-300. doi: 10.1016/S0304-3800(02)00200-4

Braunisch V, Bollmann K, Graf RF, Hirzel AH. 2008. Living on the edge-Modelling habitat suitability for species at the edge of their fundamental niche. Ecological Modelling 214(24):153-167. doi:10.1016/j.ecolmodel.2008.02.001

Braunisch V, Suchant R. 2010. Predicting species distributions based on incomplete survey data: the trade-off between precision and scale. Ecography 33(5):826-840. doi: 10.1111/j.16000587.2009.05891.x

Brooks DM, Bodmer RE, Matola S. 1997. Tapirs: Status Survey and Conservation Action Plan. IUCN/SSC Tapir Specialist Group IUCN. Gland: Switzerland and Cambridge. viii+164 p.

Clements GR, Rayan DM, Aziz SA, Kawanishi K, Traeholt C, Magintan D, Yazi MFA, Tingley R. 2012. Predicting the distribution of the Asian tapir in Peninsular Malaysia using maximum entropy modeling. Integrative Zoology 7:400-406. doi: 10.1111/j.17494877.2012.00314.x 
442 Cozzuol MA, Clozato CL, Holanda, Rodrigues FHG, Nienow S, de Thoisy B, Redondo RAF, 443 Santos FR. 2013. A new species of tapir from the Amazon. Journal of Mammalogy 94(6):1331-1345. doi: 10.1644/12-MAMM-A-169.1

Eduardo AA, Nunes AV, Brito D. 2012. Do the Protected Areas Network of the State of Minas Gerais Maintain Viable Populations of the Lowland Tapir (Tapirus terrestris)? Natureza \& Conservação 10:27-33. doi: 10.4322/natcon.2012.005

Elith J, Graham CH, Anderson RP, Dudı'k M, Ferrier S, Guisan A, Hijmans RJ, Huettmann F, Leathwick JR, Lehmann A, Li J, Lohmann LG, Loiselle BA, Manion G, Moritz C, Nakamura M, Nakazawa Y, Overton JMcC, Peterson AT, Phillips SJ, Richardson KS, Scachetti-Pereira R, Schapire RE, Sobero'n J, Williams S, Wisz MS, Zimmermann NE. 2006. Novel methods improve prediction of species' distributions from occurrence data. Ecography 29:129-151. doi: 10.1111/j.2006.0906-7590.04596.x

Elith J, Kearney M, Phillips SJ. 2010 The art of modelling range-shifting species. Methods Ecol. Evol. 1, 330-342. (doi:10.1111/j.2041-210X.2010.00036.x)

Eva HD, de Miranda EE, Di Bella CM, Gond V, Huber O, Sgrenzaroli M, Jones S, Coutinho A, Dorado A, Guimarães M, Elvidge C, Achard F, Belward AS, Bartholomé E, Baraldi A, De Grandi G, Vogt P, Fritz S, Hartley A. 2002. A Vegetation Map of South America. EUR 20159 EN, European Commission, Luxembourg. Available at http://forobs.jrc.ec.europa.eu/products/glc2000/products/final_report_v2.pdf (accessed 20 April 2015)

Florez FK, Rueda CF, Peñalosa W, Rodríguez J, Torres G, Armenta MM. 2008. Distribución Historica Y Actual de la Población de Danta de Tierras Bajas Tapirus terrestris colombianus 
(Hershkovitz 1954) mas al Norte de Sur América. The Newsletter of the IUCN/SSC Tapir Specialist Group V 17/2 No. 24.

Fragoso JMV, Huffman JM. 2000. Seed-dispersal and seedling recruitment patterns by the last Neotropical megafaunal element in Amazonia, the tapir. Journal of Tropical Ecology 16:369-385. doi: 10.1017/S0266467400001462

Fragoso JMV. 1997. Tapir-Generated Seed Shadows: Scale-Dependent Patchiness in the Amazon Rain Forest. The Journal of Ecology 85:519. doi: 10.2307/2960574

Fragoso JMV. 2005. The role of trophic interactions in community initiation, maintenance and degradation. In: Biotic Interactions in the Tropics. Their Role in the Maintenance of Species Diversity. Burslem DFRP, Pinard MA, Hartley SE (Eds.), pp. 310-327. Cambridge University Press, Cambridge.

Franklin J. 2009. Mapping species distributions. Spatial inference and prediction. Cambridge: Cambridge University Press. 336 p.

García MJ, Medici EP, Naranjo EJ, Novarino W, Leonardo RS. 2012. Distribution, habitat and adaptability of the genus Tapirus. Integrative zoology 7(4):346-55. doi: 10.1111/j.17494877.2012.00317.x

Gaston KJ. 2003. The structure and dynamics of geographic ranges. Oxford: Oxford University Press. 280 p.

Greaves GJ, Mathieu R, Seddon PJ. 2006. Predictive modelling and ground validation of the spatial distribution of the New Zealand long-tailed bat (Chalinolobus tuberculatus). Biological Conservation 132:211-221. doi: 10.1016/j.biocon.2006.04.016

Groves C, Grubb P. 2011. Ungulate taxonomy. Baltimore: The John Hopkins University Press. $336 \mathrm{p}$. 
487

488

489

490

491

492

493

494

495

496

497

498

499

500

501

502

503

504

505

506

507

Hijmans RJ, Cameron SE, Parra JL, Jones PG, Jarvis A. 2005. Very high resolution interpolated climate surfaces for global land areas. International Journal of Climatology 25:1965-1978. doi: $10.1002 /$ joc. 1276

Hirzel AH, Hausser J, Chessel D, Perrin N. 2002. Ecological-niche factor analysis: how to compute habitat-suitability maps without absence data? Ecology 83(7):2027-2036. doi: 10.1890/0012-9658(2002)083[2027:ENFAHT]2.0.CO;2

Hirzel AH, Hausser J, Perrin N. 2007. Biomapper 4.0. Lab. of Conservation Biology, Department of Ecology and Evolution, University of Lausanne, Switzerland. Available at http://www2.unil.ch/biomapper (accessed 11 February 2009).

Hirzel AH, Le Lay G, Helfer V, Radin C, Guisan A. 2006. Evaluating the ability of habitat suitability models to predict species presences. Ecological Modelling 199:142-152. doi: 10.1016/j.ecolmodel.2006.05.017

Hirzel AH, Posse B, Oggier P-A, Crettenands Y, Glenz C, Arlettaz R. 2004. Ecological requirements of reintroduced species and the implications for release policy: the case of the bearded vulture. Journal of Applied Ecology 41:1103-1116. doi: 10.1111/j.00218901.2004.00980.x

Hobbs NT. 2003. Challenges and opportunities in integrating ecological knowledge across scales. Forest Ecology and Management 181(1-2):223-238. doi:10.1016/S03781127(03)00135-X

Jackson DA. 1993. Stopping Rules in Principal Components Analysis: A Comparison of Heuristical and Statistical Approaches. Ecology 74:2204-2214. doi: 10.2307/1939574 
508 Jiménez-valverde A, Lobo JM, Hortal J. 2008. Not as good as they seem : the importance of 509 concepts in species distribution modelling. Diversity and Distributions 14:885-890. doi: $10.1111 / \mathrm{j} .1472-4642.2008 .00496 . x$

Kamino LHY, Stehmann JR, Amaral S, De Marco P Jr., Rangel TF, de Siqueira MF, De Giovanni R, Hortal J. 2011. Challenges and perspectives for species distribution modelling in the neotropics. Biology letters 8(3):324-6. doi: 10.1098/rsbl.2011.0942

Medici EP, Flesher K, Beisiegel BM, Keuroghlian A, Desbiez ALJ, Gatti A, Pontes ARM, de Campos CB, de Tófoli CF, Moraes EA Júnior, de Azevedo FC, de Pinho GM, Cordeiro JLP, da Silva Santos Júnior T, de Morais AA, Mangini PR, Rodrigues LF, de Almeida LB. 2012. Avaliação do Risco de Extinção da Anta brasileira Tapirus terrestris Linnaeus, 1758, no Brasil. Biodiversidade Brasileira Ano II, 3, 103-116.

Medici EP. 2010. Assessing the Viability of Lowland Tapir Populations in a Fragmented Landscape. D. Phil. Thesis, University of Kent, UK. xvi +276 p.

Mendoza E, Fuller TL, Thomassen HA, Ramírez-mejía D, Smith TB. 2013. A preliminary assessment of the effectiveness of the Mesoamerican Biological Corridor for protecting potential Baird's tapir (Tapirus bairdii) habitat in Southern Mexico. Integrative zoology 8(1):35-47. doi: 10.1111/1749-4877.12005

MMA. 2009. Monitoramento do Desmatamento nos Biomas Brasileiros por Satélite. Available at http://www.ministeriodomeioambiente.gov.br/florestas/controle-epreven\%C3\%A7\%C3\%A3o-do-desmatamento (accessed 13 December 2013)

Nowak RM. 1991. Walker's Mammals of the World, Vol. II, 5th ed. The Johns Hopkins University Press, Baltimore. 
530 Oliveira-Filho AT, Jarenkow JÁ, Rodal MJN. 2006. Floristic relationships of seasonally dry 531 forests of Eastern South America based on tree species distribution pasterns. In: Neotropical

532

533

534

535

536

537

538

539

540

541

542

543

544

545

546

547

548

549

550

savannas and seasonally dry forests. Penningon, R. T., Lewis, G. P. and Ratter, J. A. (Eds.), pp. 159-192. CRC Taylor \& Francis, Boca Raton.

Olson DM, Dinerstein E, Wikramanayake ED, Burgess ND, Powell GVN, Underwood EC, D'Amico JA, Itoua I, Strand H E, Morrison JC, Loucks CJ, Allnutt TF, Ricketts TH, Kura Y, Lamoreux JF, Wettengel WW, Hedao P, Kassem KR. 2001. Terrestrial Ecoregions of the World: A New Map of Life on Earth. BioScience 51:933. doi: 10.1641/00063568(2001)051[0933:TEOTWA $] 2.0 . C O ; 2$

Patterson BD, Ceballos G, Sechrest W, Tognelli MF, Brooks T, Luna L, Ortega P, Salazar I, Young BE. 2003. Digital Distribution Maps of the Mammals of the Western Hemisphere, version 1.0. NatureServe, Arlington, Virginia.

Peterson AT, Soberón J, Pearson RG, Anderson RP, Martínez-Meyer E, Nakamura M, Araújo MB. 2011. Ecological Niches and Geographic Distributions. Princeton: Princeton University Press. 328 p.

Phillips SJ, Anderson RP, Schapire RE. 2006. Maximum entropy modeling of species geographic distributions. Ecological Modelling 190(3-4):231-259.

(doi:10.1016/j.ecolmodel.2005.03.026)

Phillips SJ, Dudı M. 2008. Modeling of species distributions with Maxent : new extensions and a comprehensive evaluation. Ecography,31: 161-175. doi: 10.1111/j.2007.09067590.05203.X 
551 Phillips SJ, Dudik M, Elith J, Graham CH, Lehmann A, Leathwick J, Ferrier S. 2009. Sample

552

553 554

selection bias and presence-only distribution models: implications for background and

pseudo-absence data. Ecological Applications 19:181-197. doi.org/10.1890/07-2153.1

Rangel TF, Loyola RD. 2012. Labeling ecological niche models. Natureza \& Conservação 10: 119-126. doi:10.4322/natcon.2012.030

Rebelo H, Jones G. 2010. Ground validation of presence-only modelling with rare species: a case study on barbastelles Barbastella barbastellus (Chiroptera: Vespertilionidae). Journal of Applied Ecology 47(2):410-420. doi: 10.1111/j.1365-2664.2009.01765.x

Rodrigues M, Olmos F, Galetti M. 1993. Seed dispersal by tapir in southeastern Brazil. Mammalia (Paris) 57: 460-461.

Rodríguez-Soto C, Monroy-Vilchis O, Maiorano L, Boitani L, Faller JC, Briones MÁ, Núñez R, Rosas-Rosas O, Ceballos G, Falcucci. 2011. Predicting potential distribution of the jaguar (Panthera onca) in Mexico: identification of priority areas for conservation. Diversity and Distributions 17(2):350-361. doi: 10.1111/j.1472-4642.2010.00740.x

Schank C, Mendoza E, Vettorazzi MJG, Cove MV, Jordan CA, O`Farrill G, Meyer N, Lizcano DJ, Estrada N, Poot C, Leonardo R. 2015. Integrating current range-wide occurrence data with species distribution models to map the potential distribution of Baird's Tapir. Tapir Conservation 24: 15-25.

Simonetti JA, Huareco I. 1999. Uso de huelas para estimar diversidad y abundancia relativa de los mamíferos de la reserva de la biosfera - Estacion Biológica del Beni, Bolivia. Mastozoología Neotropical 6(1):139-144. 
572 Syfert MM, Smith MJ, Coomes DA. 2013. The effects of sampling bias and model complexity 573 on the predictive performance of MaxEnt species distribution models. PLoS ONE 8(2):e55158. doi: 10.1371/journal.pone.0055158

Taber A, Chalukian SC, Altrichter M, Minkowski K, Lizarraga L, Sanderson E, Rumiz D, Ventincinque E, Moraes EA, Angelo C, Antúnez M, Ayala G, Beck H, Bodmer R, Boher SB, Cartes JL, Bustos S, Eaton D, Emmons L, Estrada N, Oliveira LFB, Fragoso J, Garcia R, Gomez C, Gómez H, Keuroghlian K, Ledesma L, Lizcano D, Lozano C, Montenegro O, Neris N, Noss A, Vieira AP, Paviolo A, Perovic P, Portillo H, Radachowsky J, ReynaHurtado R, Rodriguez Ortiz J, Salas L, Sarmiento Duenas A, Sarria Perea JA, Schiaffino K, Thoisy B, Tobler M, Utreras V, Varela D, Wallace RB, Zapata Ríos G. 2009. El destino de los arquitectos de los bosques Neotropicales: Evaluación de la distribucíon y el estado de conservación de los pecaries labiados y los tapires de tierras bajas. Pigs, Peccaries and Hippos Specialist Group (IUCN/SSC), Tapir Specialist Group (IUCN/SSC). New York: Wildlife Conservation Society and Wildlife Trust. xxvi $+182 \mathrm{p}$.

Tirira D. 2007. Mamíferos del Ecuador. Guía de campo. Quito: Ediciones Murciélago Blanco. $576 \mathrm{p}$.

Tobler MW. 2008. The ecology of the Lowland Tapir in Madre de Dios, Peru: using new technologies to study large rainforest mammals. D. Phil. Thesis, Texas A\&M University, Texas, USA. xiv $+132 \mathrm{p}$.

TSG-IUCN. 2015. Tapir Specialist Group. Tapir Population Status. Available at http://www.tapirs.org/tapirs/index.html (accessed 17 September 2015) 
593 Krausman PR. 1997. The Influence of Landscape Scale on the Management of Desert Bighorn $594 \quad$ Sheep. In: Wildlife and Landscape Ecology: Effect of Pattern and Scale. Bissonette, J. A. 595 (Eds.), pp. 349-367. Springer-Verlag Press, New York.

596 Visser H, Nijs T. 2006. The Map Comparison Kit. Environmental Modelling \& Software 21:346597 358. doi: $10.1016 /$ j.envsoft.2004.11.013

598 Voss RS, Helgen KM, Jansa SA. 2014. Extraordinary claims require extraordinary evidence: a 599 comment on Cozzuol (2013). Journal of Mammalogy 95(4):893-898. doi: 10.1644/14$600 \quad$ MAMM-A-054

601 Wallace R, Ayala G, Viscarra M. 2012. Lowland tapir (Tapirus terrestris) distribution, activity 602 patterns and relative abundance in the Greater Madidi-Tambopata Landscape. Integrative 603 Zoology 7:407-419. doi: 10.1111/1749-4877.12010

604 WDPA. 2014. World Database on Protected Areas. IUCN-UNEP. Available at 605 http://www.protectedplanet.net/ (accessed 20 April 2015) 
607

608 Table 1. Environmental Variables (EV) used to model the potential distribution of Tapirus

609 terrestris in South America. All variables were resampled from original resolution to $0.04^{\circ}$

$610(\sim 5 \mathrm{~km})$, using the average value of all involved pixels, where the source pixels are covered by

611 the target pixel.

612

\begin{tabular}{|c|c|c|c|}
\hline Environmental Variable (EV) & Acronym & $\begin{array}{l}\text { WorldClim } \\
\text { Acronym }\end{array}$ & Source \\
\hline Annual Mean Temperature & $\mathrm{AMT}$ & BIO1 & \multirow{6}{*}{$\begin{array}{l}\text { WorldClim } \\
\text { (Hijmans et al.,2005) }\end{array}$} \\
\hline Mean Temperature of Warmest Quarter & MTWQ & BIO10 & \\
\hline Mean Temperature of Coldest Quarter & MTCQ & BIO11 & \\
\hline Annual Precipitation & AP & $\mathrm{BIO} 12$ & \\
\hline Precipitation of Wettest Quarter & PWQ & $\mathrm{BIO} 16$ & \\
\hline Precipitation of Driest Quarter & PDQ & $\mathrm{BIO} 17$ & \\
\hline Altitude - Digital Elevation Model & ALT & -- & $\begin{array}{l}\text { Shuttle Radar Topography } \\
\text { Mission } \\
\text { (http://www2.jpl.nasa.gov/srt } \\
\mathrm{m} / \text { ) }\end{array}$ \\
\hline MODIS Normalized Difference & & & \\
\hline $\begin{array}{l}\text { Vegetation Index (NDVI)-32 day } \\
\text { composites-Oct/15 - Nov/15/2004. Date } \\
\text { of the composite represents well the } \\
\text { contrast between forest and open }\end{array}$ & NDVI & -- & $\begin{array}{l}\text { Global Land Cover Facility } \\
\text { (GLCF) } \\
\text { (http://www.landcover.org/dat } \\
\text { a/modis/) }\end{array}$ \\
\hline
\end{tabular}


616 Table 2. Land Cover (remaining vegetation) and protected area network in modeled Tapirus 617 terrestris potential distribution (Consensual Potential Distribution Map, CPDM).

\begin{tabular}{|c|c|c|c|c|}
\hline $\begin{array}{l}\text { Land Cover } \\
\text { Class }\end{array}$ & $\begin{array}{l}\text { Area* } \\
\left(\mathbf{k m}^{2}\right)\end{array}$ & $\begin{array}{l}\text { Area within a } \\
\text { Strict Protection } \\
\text { protected area * } \\
\left(\mathrm{km}^{2}\right)\end{array}$ & $\begin{array}{l}\text { Area within a } \\
\text { Sustainable Use } \\
\text { protected area* } \\
\left(\mathrm{km}^{2}\right)\end{array}$ & $\begin{array}{l}\text { Protected Areas } \\
\text { network extent* } \\
\left(\mathbf{k m}^{2}\right)\end{array}$ \\
\hline Forest & $\begin{array}{l}7,003,896 \\
(52.11 \%)\end{array}$ & $\begin{array}{l}690,277 \\
(81.37 \%)\end{array}$ & $\begin{array}{l}1,927,908 \\
(82.70 \%)\end{array}$ & $2,618,185$ \\
\hline Grassland & $\begin{array}{l}2,321,326 \\
(17.27 \%)\end{array}$ & $\begin{array}{c}114,816 \\
(13.54 \%)\end{array}$ & $\begin{array}{l}219,451 \\
(9.41 \%)\end{array}$ & 334,267 \\
\hline Water & $\begin{array}{l}159,157 \\
(1.18 \%)\end{array}$ & $\begin{array}{c}8,351 \\
(0.98 \%)\end{array}$ & $\begin{array}{c}18,831 \\
(0.81 \%)\end{array}$ & 27,182 \\
\hline Anthropic & $\begin{array}{l}3,957,023 \\
(29.44 \%)\end{array}$ & $\begin{array}{l}34,834 \\
(4.11 \%)\end{array}$ & $\begin{array}{l}165,105 \\
(7.08 \%)\end{array}$ & 199,939 \\
\hline Total $\left(\mathrm{km}^{2}\right)$ & $13,441,402$ & $\begin{array}{l}848,278 \\
(6.31 \%)\end{array}$ & $\begin{array}{l}2,331,295 \\
(17.34 \%)\end{array}$ & $\begin{array}{l}3,179,573 \\
(23.66 \%)\end{array}$ \\
\hline
\end{tabular}

* values within parenthesis indicate its percentage. 
621 Table 3: South American Ecoregions (adapted from Olsonn et al.,2001), anthropic and

622 remaining natural areas in modeled Tapirus terrestris potential distribution (Consensual Potential

623 Distribution Map, CPDM).

\begin{tabular}{|c|c|c|c|}
\hline Ecoregions & $\begin{array}{c}\text { Anthropic* } \\
\left(\mathbf{k m}^{2}\right)\end{array}$ & $\begin{array}{c}\text { Remain* } \\
\left(\mathbf{k m}^{2}\right)\end{array}$ & $\begin{array}{r}\text { Total } \\
\left(\mathbf{k m}^{2}\right)\end{array}$ \\
\hline $\begin{array}{l}\text { Amazon Region - Tropical and Subtropical } \\
\text { Moist Broadleaf Forests }\end{array}$ & $\begin{array}{l}846,274 \\
(12.45)\end{array}$ & $\begin{array}{c}5,949,846 \\
(87.55) \\
\end{array}$ & $6,796,120$ \\
\hline Atlantic Forests & $\begin{array}{c}939,594 \\
(80.46)\end{array}$ & $\begin{array}{c}228,205 \\
(19.54) \\
\end{array}$ & $1,167,799$ \\
\hline Caatinga Brazilian Biome & $\begin{array}{c}478,964 \\
(66.16) \\
\end{array}$ & $\begin{array}{c}244,964 \\
(33.84)\end{array}$ & 723,928 \\
\hline Cerrado Woodlands and Savannas & $\begin{array}{c}967,354 \\
(51.15)\end{array}$ & $\begin{array}{c}923,911 \\
(48.85)\end{array}$ & $1,891,265$ \\
\hline Chiquitano Dry Forests & $\begin{array}{l}51,120 \\
(23.58) \\
\end{array}$ & $\begin{array}{l}165,718 \\
(76.42) \\
\end{array}$ & 216,838 \\
\hline Chocó Darién Moist Forests & $\begin{array}{l}55,401 \\
(69.96) \\
\end{array}$ & $\begin{array}{l}23,794 \\
(30.04)\end{array}$ & 79,195 \\
\hline Deserts and Xeric Shrublands & $\begin{array}{l}48,042 \\
(35.72) \\
\end{array}$ & $\begin{array}{l}86,460 \\
(64.28) \\
\end{array}$ & 134,502 \\
\hline Dry Chaco & $\begin{array}{l}106,582 \\
(15.77) \\
\end{array}$ & $\begin{array}{l}569,329 \\
(84.23) \\
\end{array}$ & 675,911 \\
\hline Flooded Grasslands and Savannas & $\begin{array}{l}5,398 \\
(9.76) \\
\end{array}$ & $\begin{array}{l}49,905 \\
(90.24) \\
\end{array}$ & 55,303 \\
\hline Humid Chaco & $\begin{array}{l}43,822 \\
(15.23)\end{array}$ & $\begin{array}{l}243,950 \\
(84.77)\end{array}$ & 287,772 \\
\hline Llanos Savannas & $\begin{array}{l}56,034 \\
(13.87)\end{array}$ & $\begin{array}{l}347,900 \\
(86.13)\end{array}$ & 403,934 \\
\hline Mangroves & $\begin{array}{l}14,467 \\
(31.22)\end{array}$ & $\begin{array}{l}31,874 \\
(68.78)\end{array}$ & 46,341 \\
\hline Montane Grasslands and Shrublands & $\begin{array}{c}271 \\
(5.12)\end{array}$ & $\begin{array}{c}5,024 \\
(94.88)\end{array}$ & 5,295 \\
\hline Pantanal Flooded Savannas & $\begin{array}{l}25,081 \\
(15.55)\end{array}$ & $\begin{array}{l}136,238 \\
(84.45)\end{array}$ & 161,319 \\
\hline $\begin{array}{l}\text { Temperate Grasslands, Savannas, and } \\
\text { Shrublands }\end{array}$ & $\begin{array}{l}31,516 \\
(36.57)\end{array}$ & $\begin{array}{l}54,672 \\
(63.43) \\
\end{array}$ & 86,188 \\
\hline Tropical and Subtropical Dry Broadleaf Forests & $\begin{array}{l}123,732 \\
(54.72) \\
\end{array}$ & $\begin{array}{l}102,375 \\
(45.28) \\
\end{array}$ & 226,107 \\
\hline $\begin{array}{l}\text { Tropical and Subtropical Grasslands, Savannas, } \\
\text { and Shrublands }\end{array}$ & $\begin{array}{l}163,371 \\
(33.78)\end{array}$ & $\begin{array}{l}320,214 \\
(66.22) \\
\end{array}$ & 483,585 \\
\hline Total & $\begin{array}{c}3,957,023 \\
(29.44)\end{array}$ & $\begin{array}{l}9,484,379 \\
(70.56)\end{array}$ & $13,441,402$ \\
\hline
\end{tabular}


$624 *$ values within parenthesis indicate its percentage. Adapted from Eva et al. (2002), and upgraded 625 for Brazil by MMA (2009). 
627

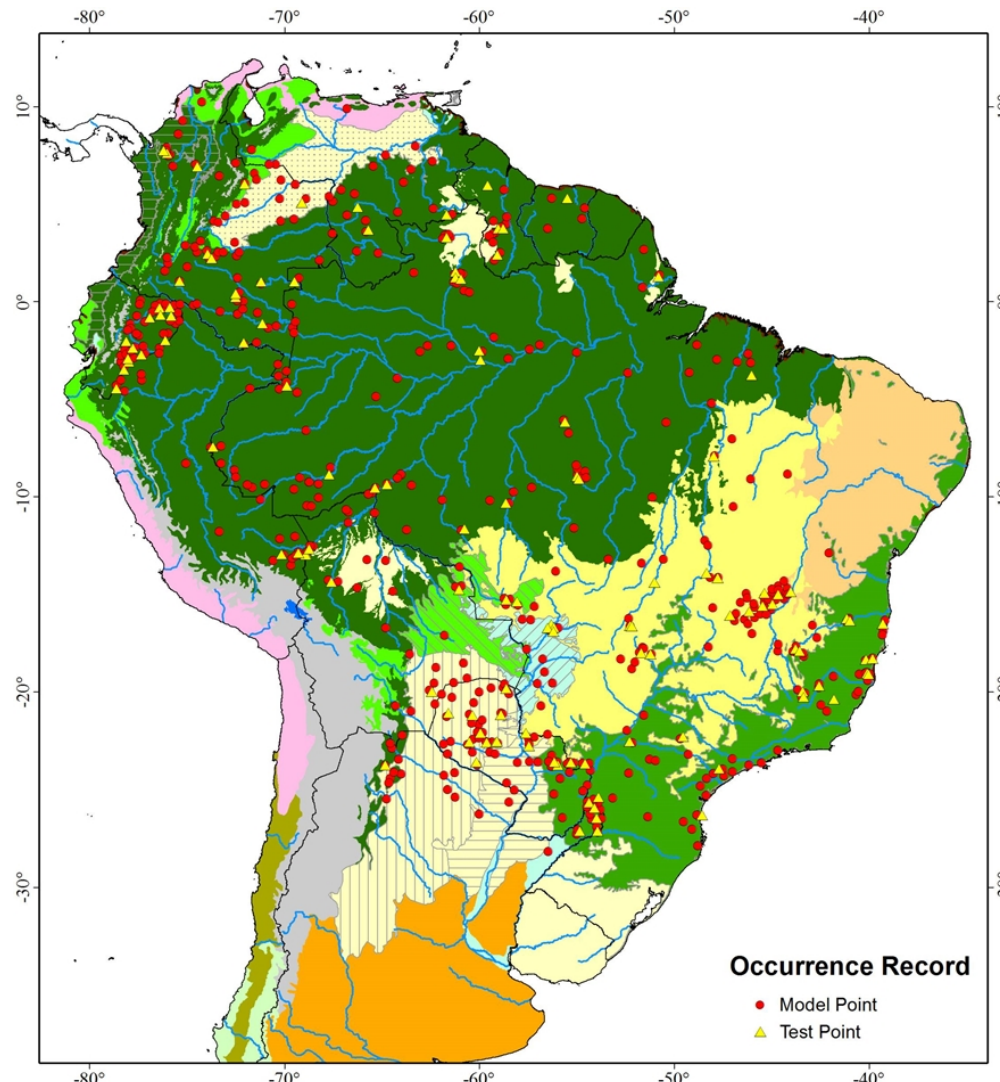

Legend

Tropical and Subtropical Moist Broadleaf Forests Atlantic Forests

Chocó-Darién Moist Forests

Tropical and Subtropical Dry Broadleaf Forests

Chiquitano Dry Forests

Temperate Broadleaf and Mixed Forests

Mediterranean Forests, Woodlands, and Scrub

Tropical and subtropical grasslands, savannas, and shrublands

Llanos Savannas

Cerrado Woodlands and Savannas

Dry Chaco

Humid Chaco

- Humid Chaco

Temperate Grasslands, Savannas, and Shrublands

Flooded Grasslands and Savannas

V/ Pantanal Wetland

Montane Grasslands and Shrublands

Deserts and Xeric Shrublands

Caatinga

Mangroves

Lake/Lagoon

Rivers

Country

$\underset{0}{500 \mathrm{1}, 000} \stackrel{N}{N}$

629 Figure 1: Terrestrial Ecoregions (adapted from Olson et al.,2001) and locations of lowland tapir 630 (Tapirus terrestris) occurrence in South America. 

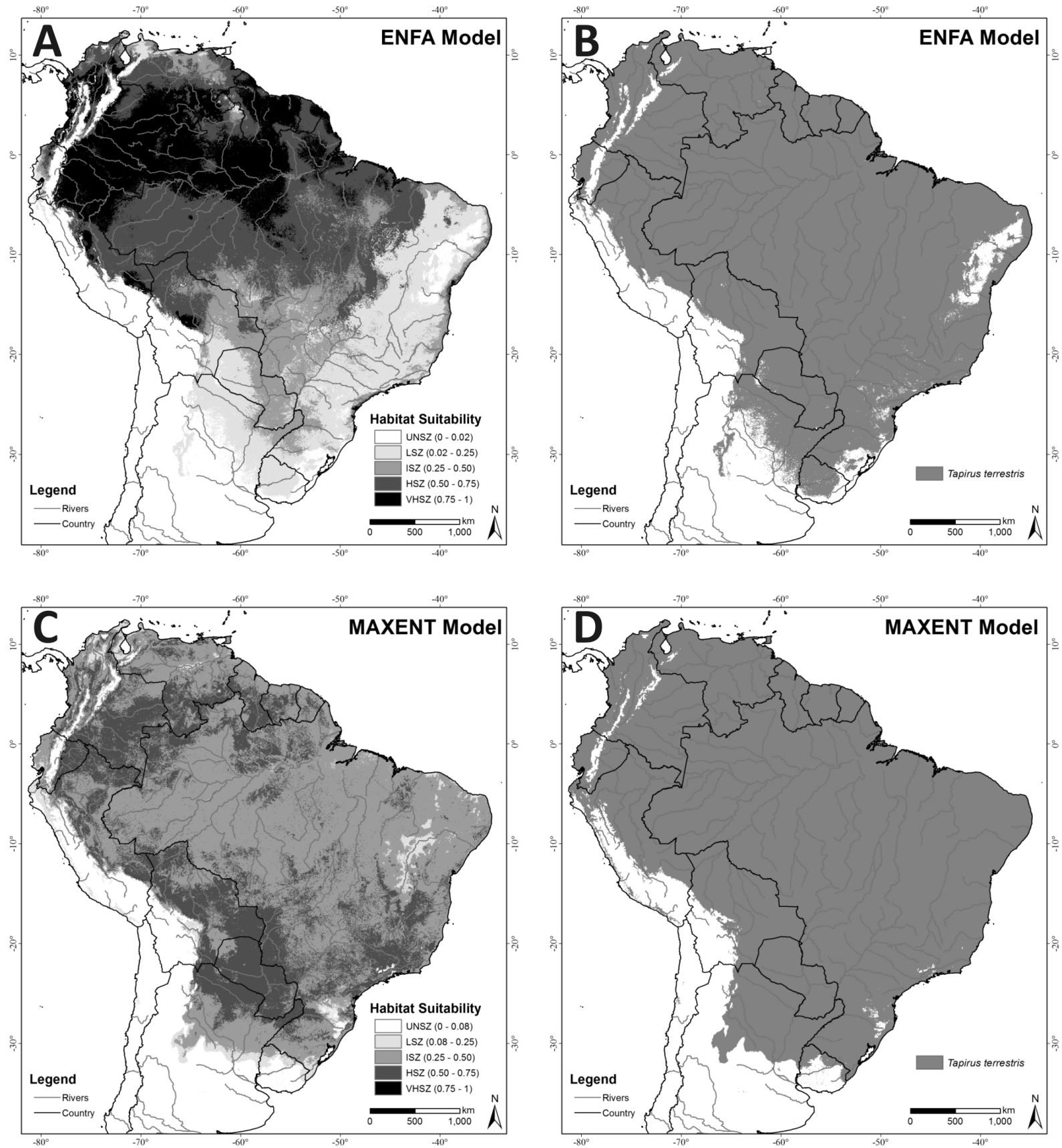

635 Figure 2: (A) ENFA Habitat Suitability Map; (B) ENFA potential distribution binary map 636 (suitable/unsuitable) based on the Minimum Training Presence cutoff criteria (MTP=0.02); (C) 637 MAXENT Habitat Suitability Map; (D) MAXENT potential distribution binary map 638 (suitable/unsuitable) based on the MTP cutoff criteria (MTP=0.08). Unsuitability Zone (UNSZ), 
639 Low Suitability Zone (LSZ), Intermediate Suitability Zone (ISZ), High Suitability Zone (HSZ), 640 and Very High Suitability Zone (VHSZ) identified. 
A

\begin{tabular}{|l|c|r|r|}
\hline Environmental Variable (EV) & Acronym & Marginality & Specialization \\
\hline Annual Mean Temperature & AMT & 0.41 & 17.64 \\
\hline Normalized Difference Vegetation Index & NDVI & 0.39 & 4.50 \\
\hline Mean Temperature of Coldest Quarter & MTCQ & 0.39 & 12.29 \\
\hline Annual Precipitation & AP & 0.38 & 5.55 \\
\hline Mean Temperature of Warmest Quarter & MTWQ & 0.38 & 12.32 \\
\hline Precipitation of Wettest Quarter & PWQ & 0.35 & 4.63 \\
\hline Precipitation of Driest Quarter & PDQ & 0.28 & 3.70 \\
\hline Altitude & ALT & -0.21 & 6.05 \\
\hline
\end{tabular}

B

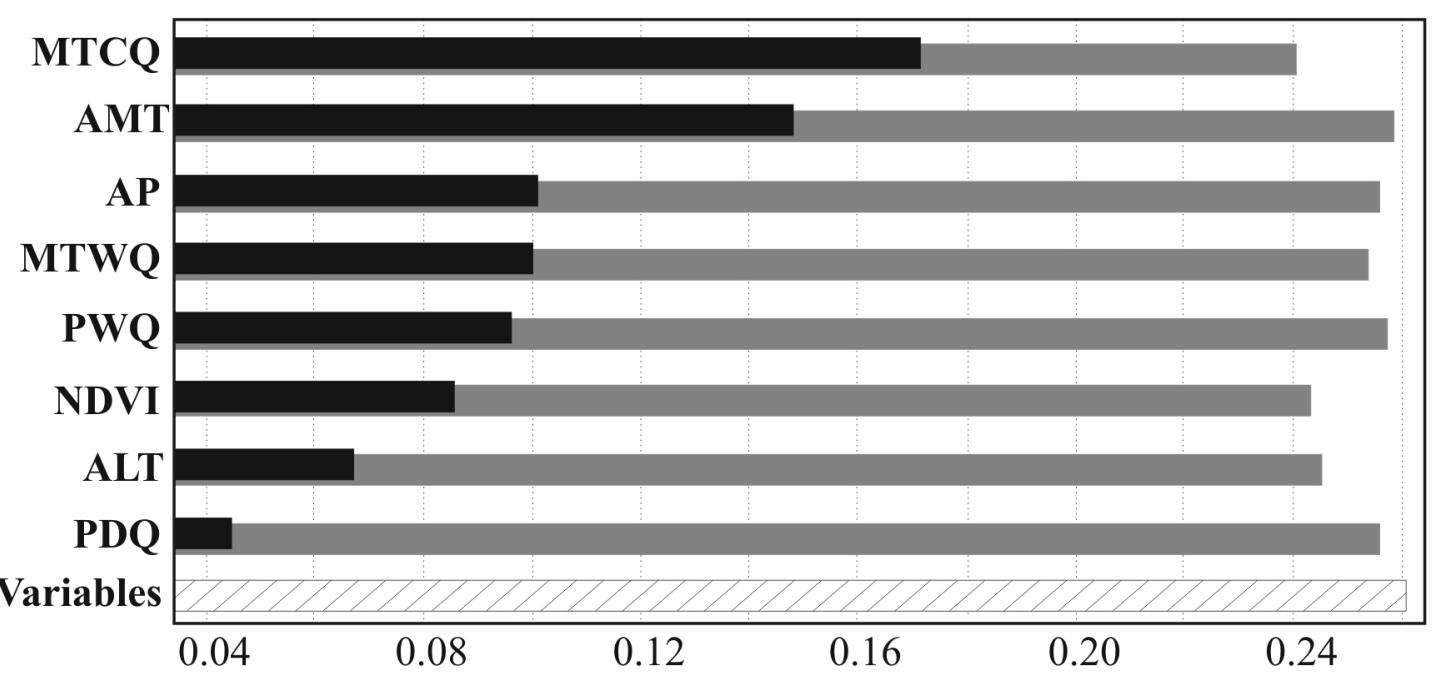

645 Figure 3: (A) The relative contribution of Environmental Variables (EV) to the ENFA 646 Marginality and Specialization factors - EVs are sorted by decreasing absolute value of 647 coefficients on the marginality factor. Positive values on this factor mean that T. terrestris 648 prefers locations with higher values on the corresponding EV than the average value in the study 649 area. Signs of coefficient have no meaning for the specialization factors. (B) Jackknife test 650 results of individual environmental variable importance in the development of the MAXENT 
651 model relative to all environmental variables (hactched bar), for each predictor variable alone

652 (black bars), and the drop in training gain when the variable is removed from the full model 653 (gray bars). 

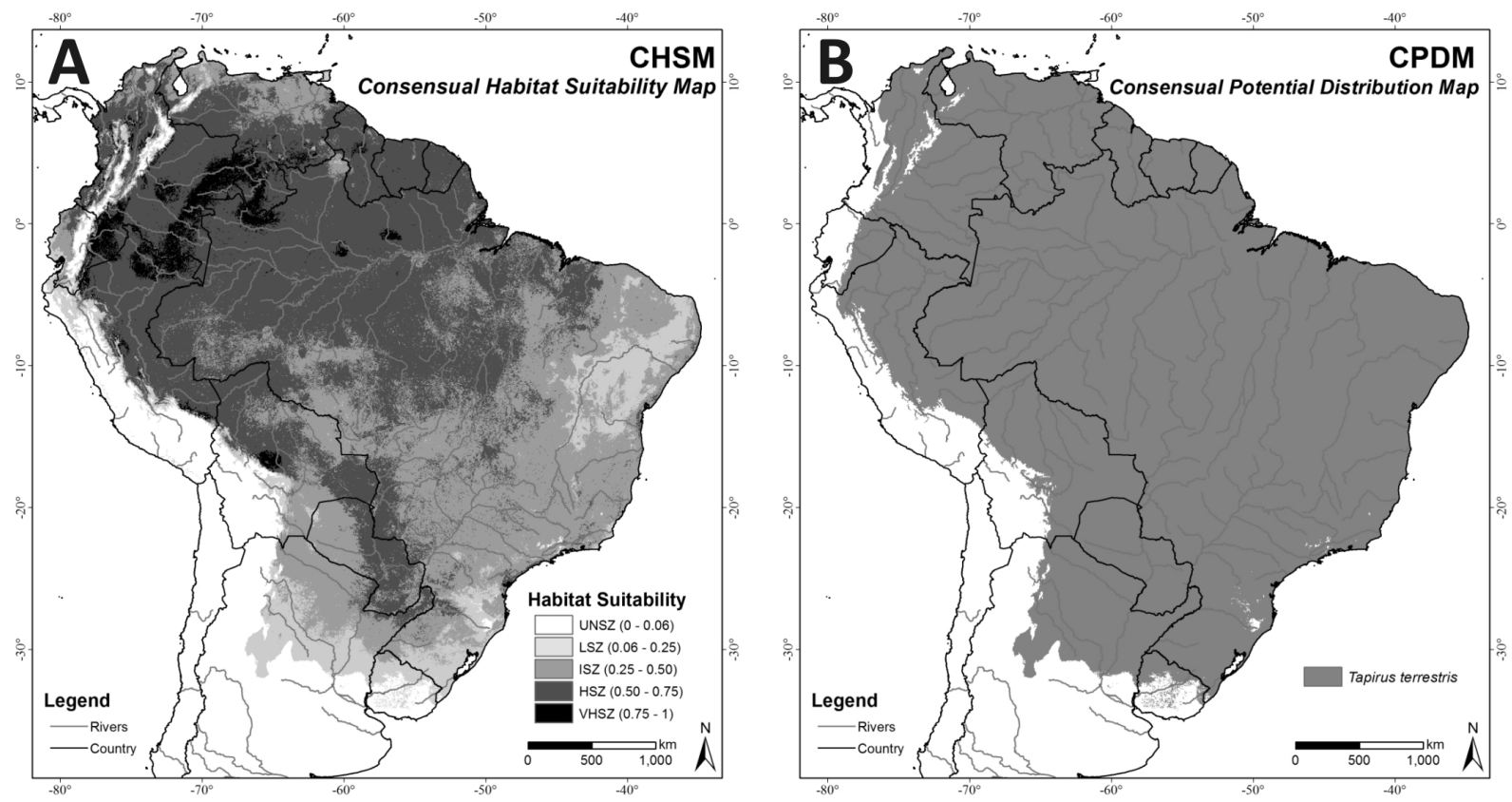

Figure 4: (A) Consensual Habitat Suitability Map, CHSM; (B) Consensual Potential Distribution Map, CPDM (suitable/unsuitable), based on the Minimum Training Presence cutoff criteria (MTP=0.06). Unsuitability Zone (UNSZ), Low Suitability Zone (LSZ), Intermediate Suitability Zone (ISZ), High Suitability Zone (HSZ), and Very High Suitability Zone (VHSZ) identified. 